\title{
Complementing the Scoping Process of Configuration Projects by Design Thinking
}

\author{
Sara SHAFIEE ${ }^{\mathrm{a}, 1}$, Anders HAUG ${ }^{\mathrm{b}}$, Saeedeh SHAFIEE KRISTENSEN ${ }^{\mathrm{c}}$, Lars HVAM ${ }^{\mathrm{d}}$ \\ and Niels Henrik MORTENSEN ${ }^{\mathrm{a}}$ \\ ${ }^{a}$ Department of Mechanical Engineering, Technical University of Denmark, Denmark \\ ${ }^{\mathrm{b}}$ Department of Entrepreneurship and Relationship Management, University of \\ Southern Denmark, Denmark \\ ${ }^{c}$ DTU Business, Technical University of Denmark, Denmark \\ ${ }^{\mathrm{d}}$ Department of Management Engineering, Technical University of Denmark, Denmark
}

\begin{abstract}
Configurators are expert systems that support product customization by defining how predefined entities and their properties can be combined. Configurators support decision-making processes in the sales and engineering phases of a product and bring substantial benefits, such as shorter lead times, fewer errors, increased ability to meet customers' requirements and more. Developers of configuration systems act as designers, albeit often not recognizing they are performing in a design process. They define the project scope and the distinction between the problem and solution space elucidates the dualistic approach of Design Thinking (DT). DT is a human-centered approach that includes a wide perspective of stakeholders and aims at enhancing human experience and solving complicated problems by exploring both the problem and solution space. However, exploration of the solution space is typically not a big part of configuration projects, where instead the focus is on mapping the existing knowledge to the configurator. Thus, this paper investigates if the use of DT can make the configuration engineers more inclined to develop new and improved product solutions before implementing knowledge into the configurator. Firstly, the paper reviews the DT literature and discusses its potential applications in configuration projects. Secondly, the paper studies three configuration projects in which DT has been applied. Next, the case studies are compared to existing configuration projects described in the literature. The results of analysis showed that the application of DT promoted increased exploration of the solution space and better communication within organization, and that this led to improved product solutions.
\end{abstract}

Keywords. Configuration, Design Thinking, Scoping, Knowledge Management, Problem and Solution Space

\section{Introduction}

Product Configuration Systems are attracting increased attention as they can support customer-oriented business processes with regard to the specification of products [1]. Configurators support decision-making processes in the sales and engineering phases of a product [1]. Widely used in various industries, configurators can bring substantial benefits, such as shorter lead times for generating quotations, fewer errors, increased ability to meet customers' requirements regarding product functionality, the use of fewer resources, optimized product designs, less routine work and improved on-time delivery [2]-[4]. Based on literature, there are various challenges reported on managing different

\footnotetext{
${ }^{1}$ Corresponding Author, Email: sashaf@dtu.dk.
} 
phases of configuration projects [5], [6]. There are researchers focusing on improving configuration projects process including knowledge management (KM) [7]-[9].

In configuration projects, scoping and KM involve the entire life cycle of knowledge, from acquisition [10], [11] to modelling, validating, testing and finally to documenting and updating. Hence, it concerns both domain experts and the configuration team as the internal stakeholders [12]. Configuration teams include knowledge engineers, modelers, developers and project managers working on configuration projects [1].

The knowledge required for configuration projects is normally very specialized product knowledge that lies beyond the configuration team's expertise [13]-[15]. Knowledge formalization and communication in configuration projects correspond to product modelling, which is a method of representing the structure and knowledge of the product on a relatively visual, abstract level to ensure that they are understandable to all persons concerned [9]. Moreover, the knowledge modelled in configuration projects is extensive and must be continually validated by domain experts [16]. Strong communication between the configuration team and domain experts in configuration projects is vital, and specific modelling techniques tend to meet this challenge in configuration projects [17].

Developing and implementing a configurator is a collective task that involves and accommodates the participation of different internal stakeholders from different divisions within the organization. Hence, the social dimension for design relies on stakeholders' understanding of the system, the strong interaction among R\&D, marketing, IT team and domain experts and the designation of multidisciplinary teams. Design intends to offer more concrete solutions to complex and socially ambiguous problems.

Solutions and frameworks offered to solve the scoping and KM challenges mostly involve a dominant technical perspective; however, the KM challenge seems to be more social and organizational. According to Lindberg et al. [18], the days when IT-based products pushed technological dynamics has become a thing of the past; now they are perceived as deeply dependent on social life dynamics and strong team-based collaboration as a core feature of agile development.

The idea behind applying DT to KM tasks in configuration projects asks for setting up a complementary thinking style which extends the collaboration and communication abilities of domain experts and configuration team with the purpose of making their outcomes more innovative. The point is that verbal and written communication does not suffice to support scoping, dialogue and acquisition of knowledge in these projects. There are requirements from the users, which should be applied during the configurators' development. DT provides tools such as journey mapping, sketches, porotypes, diagrams and models as visual and tactile representations for communicating, evaluating and acquiring knowledge and ideas. In this paper we focus on how to relate DT to the structures, cultures and development processes of configuration projects- in particular regarding the social aspects in scoping and KM phase. Building upon this argumentation, the main research question is:

How can principles of DT support the scoping and KM process of configuration projects? 


\section{Related work}

\subsection{Design thinking}

Design thinking (DT) is a human-centered approach that includes a wide perspective of stakeholders, including internal (within the team and more broadly within the firm) or external, and it aims at enhancing human experience and solving complicated problems [19]. The distinction between the problem and solution space elucidates the dualistic approach of design thinking which aims at finding a novel solution that fits a social and/or technical system [18]. Therefore, it may contribute to solving KM-related challenges in configuration projects, which are mainly related to communication within the organization that follows a systematic and iterative design approach. According to Lockwood (2010), DT is "a human-centered innovation process that emphasizes observation, collaboration, fast learning, visualization of ideas, rapid concept prototyping, and concurrent business analysis."

The word "software design" is, in fact, one of the few design terms that are almost exclusively associated with technical issues [18]. Configuration projects development process can be defined as: getting a comprehensive understanding of (1) what the product will look like, (2) if solutions will work or not, and (3) how the conditions of interaction between user and software can be shaped, generally presupposing the ability to communicate about those questions in technical terms [18]. One basic problem, for instance, is that functionalities and user interfaces, albeit technically perfect, may shape up as incomprehensible or inappropriate from the user's point of view [18]. An isolated technical perspective entailing isolated analytical thinking can thus lead into an innovation trap of spending too much effort on the development of technically novel solutions that the clients cannot see the distinctive value in [18], [21]. Applying DT to IT-development asks for setting up a complementary thinking style, which extends the problem solving abilities of IT development teams with the purpose of making their outcomes more innovative [18].

\subsection{Design thinking for IT development}

The idea behind applying design thinking to IT development asks for setting up a complementary thinking style, which extends the problem solving abilities of IT development teams with the purpose of making their outcomes more innovative [18]. There are few researchers addressing the integration of Scrum or Agile with design thinking in IT projects [22]. Hager and Hirschfeld et al. both tested their idea in case studies. The DT team combines the important insights from different interviews and serves as a representative of the target group to the innovation team and ideates aspects of a possible solution and prototypes these. To initiate Ideation, the team should brainstorm on so called How Might We Questions, which can be derived from the team's Point of View [23]. Each prototype will undergo intensive tests with target users. The information gained by testing the ideas needs to be synthesized again. Depending on the outcome of this Synthesis phase, the team will start a consecutive Iteration in which it will move on with further ideation to refine the idea or, go back to Understand and Observe phases to answer open questions and investigate new aspects of the problem [23]-[25]. DT can be described by three basic characteristics [18]: 
1. Exploring the problem space: When exploring a problem space, DT acquires an intuitive (not fully verbalized) understanding, mainly by observing exemplary use cases or scenarios, as opposed to formulating general hypotheses or theories regarding the problem; and synthesize this knowledge to point of views.

2. Exploring the solution space: DT asks for a great number of alternative ideas in parallel and elaborates them with sketching and prototyping techniques. In this manner, ideas are being consciously transformed into tangible representatives.

3. Iterative alignment of both spaces: These representatives of ideas and concepts facilitate communication not only in the design team, but with users, clients and experts as well. Thus, DT helps to keep in touch with the problem-relevant environment and can use this information for refining and revising the chosen solution path(s).

The three processes, described above, are illustrated in Figure 1.

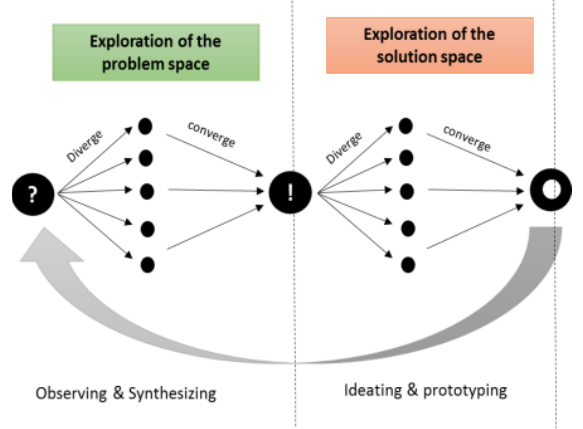

Figure 1. Exploration of problem and solution spaces [18].

\section{Design thinking for configuration projects scoping}

With a basis in the perspective on design thinking illustrated in Figure 1, a similar logic may be used to illustrate configuration projects, as shown in Figure 2. The basis of the process is an empty configurator shell, i.e., configurator software in which product knowledge has not yet been modelled. In this configurator shell, configurator developers define parts, modules, attributes and their relationships, thereby constructing the solutions space of the configurator. When the configurator is put into operation, users make product choices inside this solution space until they arrive at the customized product of their choice, i.e., a particular product instance within this space.

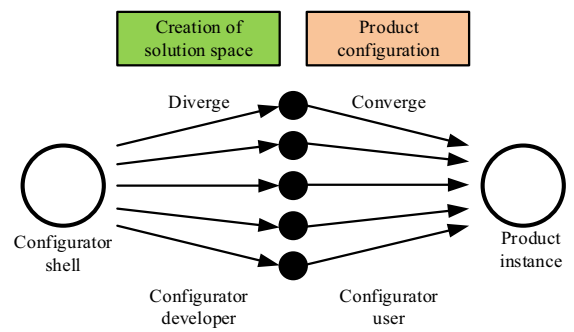

Figure 2. Divergence and convergence in configurator projects. 
In configuration projects, regardless of the management methods used (waterfall, Scrum, RUP, etc.), the configuration team seeks to limit the divergent thinking in order to be able to control the process and ensure progress. Hence, to be able to manage and control the project time and resources, they, to a large extent, limit the solutions to the experiences from previous solutions instead of considering new ideas. In this paper, we introduce design thinking in order to establish focus of an expert's world and ask for the integration of further perspectives on problem understanding and solution finding. Thus, the idea behind applying design thinking to configuration project is to set up a complementary meta-disciplinary thinking style. One of the arguments why design thinking can properly work is the multiple iterations in the initial stages of the project, where the costs are much lower. Thus, the project scope will be focused on gaining feedback in each early iteration from all involved stakeholders.

The failures in configuration projects [26]-[28] address this fact that there are a lot of features from users' perspective that have to be considered during configuration projects scoping and development. Shafiee et al. [29] propose an iterative framework for scoping and managing knowledge in configuration projects. Figure 3 illustrates the IT development and the KM framework for configuration projects.

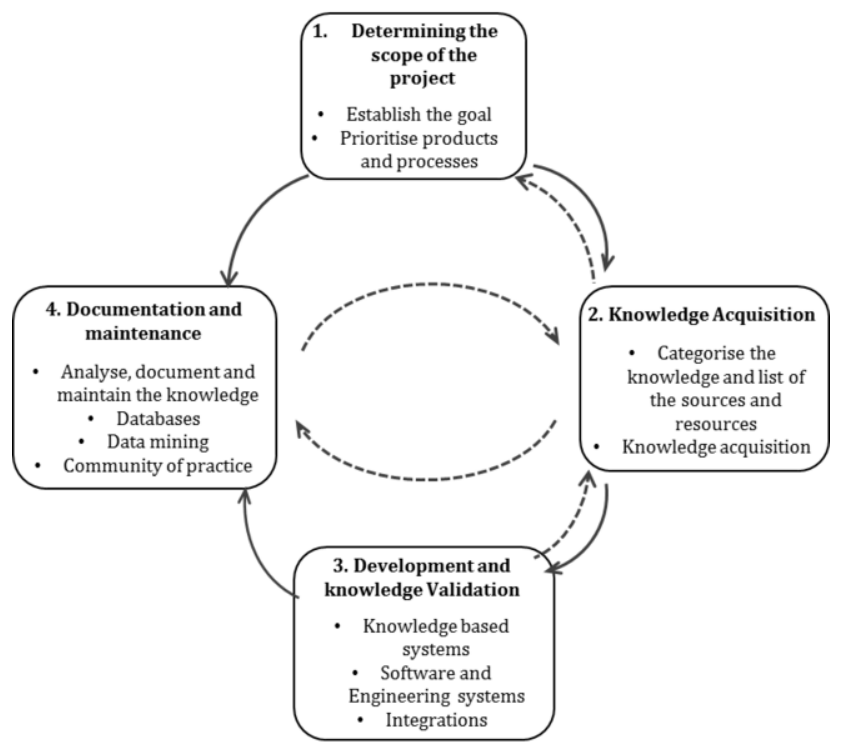

Figure 3. Knowledge management framework for configuration projects [29].

\section{Development of conceptual framework}

As stated in the Introduction, the aim of this paper is apply DT to the KM part of configuration projects. The authors 'ultimate goal is to outline what the contribution of DT to configuration projects can be and discuss its importance in promoting the collaboration and communication of knowledge within the organization.

As previously argued, using DT elements in configuration projects may help solving some of the challenges encountered. This is illustrated in Figure 4, which demonstrates the merged version of the configuration framework and the DT method. As demonstrated 
in Figure 4, the DT method is used as a complementary thinking style on top of the proposed framework.

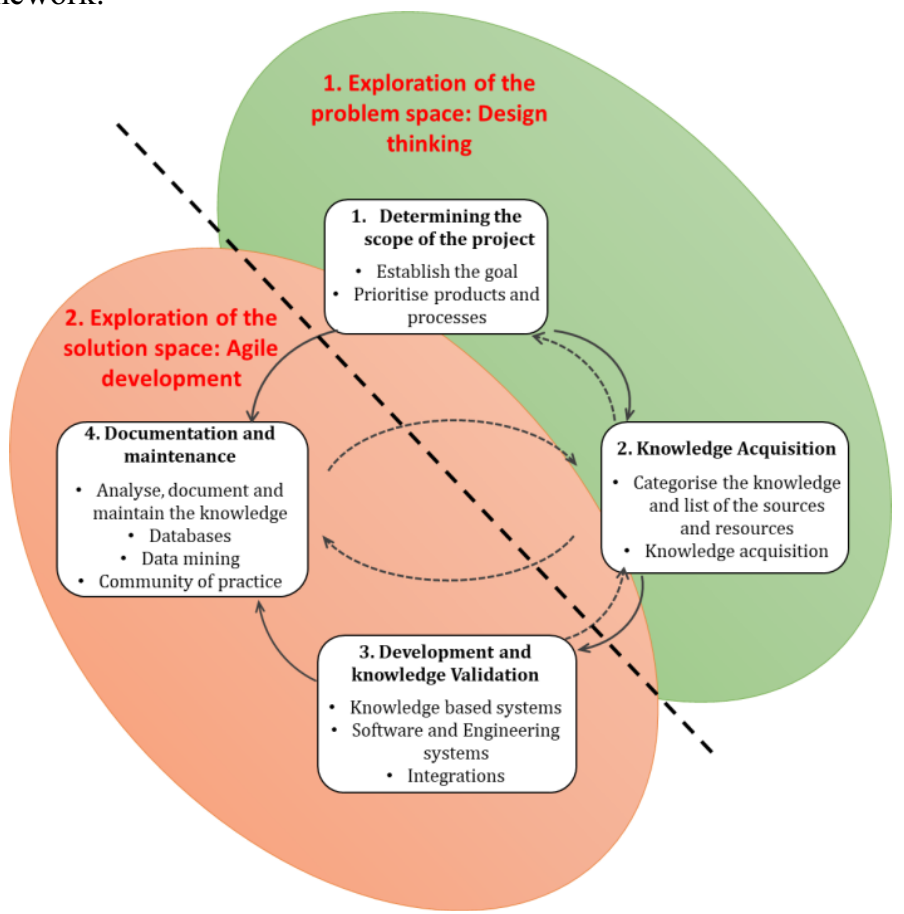

Figure 4. Applying design thinking to scoping and knowledge management process in configuration projects.

One step deeper, DT methods can be integrated into configuration projects. This is illustrated in Table 1, which shows DT phases in relation to configuration projects. The table also summarizes relevant design research and suggests tools and methods for each of the stages.

The procedure described in Table 1 represents a novel approach to product configuration projects, which needs to be further investigated by future research. Because of the large emphasis on explorations of problem and solutions spaces, one expected outcome of the application of this process would be configurators that to a higher extent correspond with the "worldview" of configurator users, and thus have higher success rates.

\section{Results and discussions}

We used a qualitative exploratory design based on multiple data sources: case study, workshops, and participant observation [30], [31]. The study is ongoing in one case company using DT method for developing configuration systems during KM process. Workshops are conducted to train the team for DT to be implemented during KM. Finally, feedback meetings and workshops are held to collect knowledge about the team's satisfaction with applying DT during KM process of configuration systems as well as the challenges and drawbacks. We formulated some propositions that can form the basis for an agenda for further experimentation and empirical research crossing KM and DT approaches in innovative firms. 
We chose three configuration project from an engineering company to evaluate the DT application. The case company, which operates globally, specializes in catalyst production and process-plant technology. This study selected three case companies using the following selection criteria: (1) produces complex and highly-engineered building elements or components, (2) potential and interest in using DT for KM from stakeholders, (3) potential access exists to senior experts and potential users, and (4) top managers in the case companies will sponsor and support all the projects. Typically, the primary sources of data in case study research are through interviews and interactions; other sources of data include personal observations, informal conservations, and attending the meetings and reviews of the archival sources [32].

Table 1. Applying design thinking methods in scoping and $\mathrm{KM}$ of configuration projects.

\begin{tabular}{|c|c|c|c|}
\hline $\begin{array}{l}\text { Design } \\
\text { thinking } \\
\text { phases }\end{array}$ & $\begin{array}{c}\text { Scoping and } \\
\text { KM in } \\
\text { configuration } \\
\text { projects }\end{array}$ & Design research & Suggested methods and tools \\
\hline
\end{tabular}

\begin{tabular}{cccc} 
Determining & $\begin{array}{l}\text { Seek to understand culture, } \\
\text { experiences, emotions, thoughts, } \\
\text { and behavior: } \\
\text { the scope of } \\
\text { the project } \\
\begin{array}{c}\text { Exploring } \\
\text { the } \\
\text { problem } \\
\text { space }\end{array}\end{array}$ & $\begin{array}{l}\text { What are the user experiences? } \\
\text { What will make them happy in } \\
\text { achieving goals? }\end{array}$ & $\begin{array}{l}\text { Applying qualitative research } \\
\text { methods such as ethnography, } \\
\text { participant observation, interviews, } \\
\text { journey mapping, job-to-be-done } \\
\text { analysis, mind mapping to facilitate } \\
\text { drawing insights from ethnographic } \\
\text { data and to create a "common } \\
\text { mind" across team members, using } \\
\text { collaborative ideation such as } \\
\text { brainstorming and concept } \\
\text { development techniques }\end{array}$ \\
\cline { 2 - 4 } & $\begin{array}{l}\text { Knowledge } \\
\text { acquisition }\end{array}$ & $\begin{array}{l}\text { Primarily through semi- } \\
\text { structured conversations between } \\
\text { the researcher and the } \\
\text { interviewed. Definition of } \\
\text { integrations, architecture and user } \\
\text { interface. }\end{array}$ &
\end{tabular}

\begin{tabular}{|c|c|c|c|}
\hline \multirow{2}{*}{$\begin{array}{l}\text { Exploring } \\
\text { the } \\
\text { solution } \\
\text { space }\end{array}$} & $\begin{array}{l}\text { Development } \\
\text { and knowledge } \\
\text { validation }\end{array}$ & $\begin{array}{l}\text { Represents samples qualitatively } \\
\text { and seeks profiles of extreme } \\
\text { users, as unusual observations } \\
\text { may lead to novel ideas }\end{array}$ & \multirow{2}{*}{$\begin{array}{l}\text { Identifying assumptions: } \\
\text { assumptions around value creation, } \\
\text { execution, scalability, and } \\
\text { defensibility that underlie the } \\
\text { attractiveness of a new idea } \\
\text { Prototyping: techniques that } \\
\text { facilitate making abstract ideas } \\
\text { tangible (storyboarding, user } \\
\text { scenarios, metaphor, experience } \\
\text { journeys, business concept } \\
\text { illustrations, and so on) }\end{array}$} \\
\hline & $\begin{array}{l}\text { Documentation } \\
\text { and knowledge } \\
\text { maintenance }\end{array}$ & $\begin{array}{l}\text { Investigation on behavior, objects } \\
\text { and words that people use to } \\
\text { express the way they interact with } \\
\text { the system }\end{array}$ & \\
\hline \multicolumn{2}{|c|}{$\begin{array}{c}\text { Iterative alignment of } \\
\text { both spaces }\end{array}$} & $\begin{array}{l}\text { Exploring people's opinions and } \\
\text { behaviors regarding current } \\
\text { situations or expectations of } \\
\text { future contexts. }\end{array}$ & $\begin{array}{l}\text { Applying field experiments: testing } \\
\text { the key underlying and value- } \\
\text { generating assumptions of a } \\
\text { hypothesis in the field with } \\
\text { stakeholders }\end{array}$ \\
\hline
\end{tabular}

The steps in Table 1 was utilized to apply DT phases during the KM process of configuration projects. We did some preliminary prototyping and tested different ideas that could be just a drawing or as very minor development to illustrate the inputs and the 
user interface. In the next step, we prioritized the requirements from stakeholders. The case studies allowed us to evaluate the application of DT in configuration projects and compare the results with the current situations at the case company where they do not use DT for developing configuration projects.

The selected projects involved with very complicated engineering design of a chemical product and included different stakeholders with different expertise. The company develops configurators to support the sales and production process internally. Hence, the end users of the system are the engineers at the company. The KM process also requires collaboration between all the involved resources with different backgrounds and expectations. Based on the experiences at the case company, there is always the risk of the rejection of configuration system due to lack of satisfaction from stakeholders and end-users.

\section{Results and discussions}

We analyzed DT along a social dimension referring to the stakeholders involved in the $\mathrm{KM}$ process. Focusing on internal stakeholders in this stage of configuration projects, we suggested how DT could provide significant contributions to the challenges they encounter. DT emphasizes the iterative identification of stakeholders and promotes frequent and rich interactions with them, involving several artifacts such as stimulators to develop empathy [33].

The steps in Table 1 was utilized to apply DT phases during the KM process of configuration projects. There are, indeed, some observations from the case studies which can be addressed while discussing and presenting prototypes in different workshops. There are also some points and indications mentioned by different stakeholders comparing the previous methods of KM with and without DT application in developing configuration projects. The interpretations from the case study are listed below:

1. Supporting KM process with DT needs additional time and resources.

2. Supporting KM process with DT decreases the development time.

3. DT gives a very clear definition of the problem to IT team and the stakeholders for a better and easier understanding of what they need and what should their expectations be. Many good solutions failed due to the lack of a meaningful problem space.

4. DT can be really helpful for describing and validating the problem domain. Once you have developed a few prototypes and successfully tested them, everyone could gain a profound understanding of what the perfect final solution should look like.

5. Normally the solution designed based on the IT team understandings is different from what the users need. DT can take the role of a meta-disciplinary rational, which allows a team across the disciplines to develop a mutual and general understanding of problem and solution.

6. It is difficult to determine the level of details in configuration projects, and DT enables the IT team to scope the project more easily.

7. The IT team manager managed to align the stakeholder and implement the system easier and manage the changes at the company by using DT and involving the users while designing the system.

8. The IT team, previously, did some projects two or even three times as they did not have a clear understanding from what the users need or they were just receiving the feedbacks from few of stakeholders and not all of them. 


\section{Conclusions}

In this research, we have found some preliminary test results from the case company developing configuration projects. Accordingly, DT can support the scoping and KM process of configuration systems. Therefore, the research project is still ongoing for more case configuration projects to involve the internal stakeholders in different workshops. The results of the workshops and interviews shape the next steps of the research. In this stage, the team initiate with planning for the ideation and prototyping involving the configuration team and the next step of the research will involve the whole company for analyzing the behavior and value generation.

First, we defined the potential users of the system. We defined the states in which the user accesses DT and tried to have a common understanding of the expectation from the configuration system. In this stage and during several workshops, we defined the problem from different perspectives. Second, we start to do some prototyping of the future deliverable configuration system. This was a very quick and effective way of initiating to design the solution. Based on the stakeholders' comments, this prototype helped them to realize their future expectations through:

1. providing the visual guide to a website which helps stakeholders look at layout without thinking about the aesthetics of the project

2. creating a consistent level of features or pages to test with user, management team, other colleagues, etc.

3. addressing and testing all the doubts and wonderings that starts to appear as the IT team design a feature in details

4. facilitating the life of the developers/testers - the prototype will (in details) specify interactions, feedback, notifications, as this is a part of the user journey for the task.

While developing the configuration system, the users provided us with the frequent comments and feedback while testing the system which has been addressed in section 4 . The final step which is the ongoing process in our research will be to test the final version of the configuration system and to ask for regular feedbacks. In this stage, we will investigate if the users can figure out how to use the configuration system to the maximum potentials as the influence of DT. Change management challenges will also be compared to the previous status. Therefore, we will collect data via questionnaires and interviews with the users and test tasks that give us the opportunity to observe the answers during the users' interactions.

\section{References}

[1] L. Hvam, N. H. Mortensen and J. Riis, Product customization, Product Customization, vol. 51, pp. $1-283,2008$.

[2] L. Hvam, S. Pape and M. K. Nielsen, Improving the quotation process with product configuration, Computers in Industry, vol. 57, no. 7, pp. 607-621, Sep. 2006.

[3] T.D. Petersen, Product configuration in ETO companies, in: T. Blecker (ed.) Mass customization information systems in business, IGI Global, Singapore, 2007, pp. 59-76.

[4] F. Salvador and C. Forza, Configuring products to address the customization-responsiveness squeeze: A survey of management issues and opportunities, International Journal of Production Economics, vol. 91, no. 3, pp. 273-291, Oct. 2004.

[5] L.L. Zhang, Product configuration: a review of the state-of-the-art and future research, International Journal of Production Research, vol. 52, no. 21, pp. 6381-6398, Aug. 2014.

[6] A. Felfernig, L. Hotz, C. Bagley and J. Tiihonen, Knowledge-Based Configuration From Research to Business Cases. Morgan Kaufman, Newnes, 2014. 
[7] S. Shafiee, Conceptual Modelling for Product Configuration Systems, PhD thesis, Technical University of Denmark, 2017.

[8] S. Shafiee, K. Kristjansdottir, and L. Hvam, Automatic identification of similarities across products to improve the configuration process in ETO companies, International Journal of Industrial Engineering and Management, vol. 8, no. 3, 2017, pp. 167-176.

[9] S. Shafiee, L. Hvam, A. Haug, M. Dam, and K. Kristjansdottir, The documentation of product configuration systems: A framework and an IT solution, Advanced Engineering Informatics, 2017, vol. 32, pp. 163-175.

[10] J. Tiihonen, T. Soininen, T. Männistö and R. Sulonen, State-of-the-Practice in Product Configuration - A Survey of 10 Cases in the Finnish Industry, in Knowledge Intensive CAD, 1996, vol. 1, pp. 95114.

[11] D. Bernhardt, Q. Liu and K. Serfes, Product customization, European Economic Review, vol. 51, no. 6, pp. 1396-1422., 2004.

[12] V.E. Barker, D.E. O'Connor, J. Bachant and E. Soloway, Expert systems for configuration at Digital: XCON and beyond, Communications of the ACM, vol. 32, no. 3, pp. 298-318, Mar. 1989.

[13] R. Studer, V.R. Benjaminsc, and D. Fensela, Knowledge engineering: Principles and methods, Data \& Knowledge Engineering, vol. 25, no. 1-2, pp. 161-197, 1998.

[14] A. Haug, Representation of Industrial Knowledge-as a Basis for Developing and Maintaning Product Configurators, PhD thesis, Technical University of Denmark, 2008.

[15] I. Nonaka, A dynamic theory of organizational knowledge creation, Organization science, vol. 5, no. 1, pp. 14-37, 1994.

[16] V. R. Basili and D. M. Weiss, A Methodology for Collecting Valid Software Engineering Data, IEEE Transactions on Software Engineering, vol. SE-10, no. 6, pp. 728-738, 1984.

[17] C. Forza and F. Salvador, Managing for variety in the order acquisition and fulfilment process: The contribution of product configuration systems, International Journal of Production Economics, vol. 76, no. 1, pp. 87-98, Mar. 2002.

[18] T. Lindberg, C. Meinel, and R. Wagner, Design thinking: A fruitful concept for IT development, in C. Meinel, L. Leifer and H. Plattner (eds.) Design thinking, Springer, Berlin Heidelberg, 2011, pp. 3-18.

[19] J. Kolko, Exposing the magic of design: a practitioner's guide to the methods and theory of synthesis. Oxford University Press, Boston, 2011.

[20] T. Lockwood, Design thinking: Integrating innovation, customer experience, and brand value. Allworth Press, New York, 2010.

[21] Y.W. Song, J.D. Kim, L. Yu, H.K. Lee and H.S. Lee, A comparative study of the telematics industry in Korea and China, Journal of Internet Banking and Commerce, vol. 17, no. 1, pp. 144-156, 2012.

[22] F. Häger, T. Kowark, J. Krüger, C. Vetterli, F. Übernickel and M. Uflacker, "DT@ Scrum: integrating design thinking with software development processes," in H. Plattner, C. Meinel, L. Leifer, Design thinking research, Springer Nature Switzerland, 2015, pp. 263-289.

[23] C. Vetterli et al., Jumpstarting scrum with design thinking. University of St.Gallen, 2013.

[24] H. Plattner, C. Meinel and L. Leifer, Design Thinking Research:Building Innovators. Springer International Publishing, 2015.

[25] C. H. Dorst, Design problems and design paradoxes, Design issues, vol. 22, no. 3, pp. 4-17, 2006.

[26] P. Blazek and K. Pilsle, Learnings From Setting Up Product Configurator Projects, Annals of the Faculty of Engineering Hunedoara - International Journal of Engineering, vol. 15, no. 1, pp. 25-28, 2017.

[27] D. Walcher and L. Werger, Why MC Organizations Fail-The Classification of Failure Reasons, in 2011 World Conference on Mass Customization, Personalization, and Co-Creation MCPC, 2012.

[28] A. Haug, S. Shafiee, and L. Hvam, "The causes of product configuration project failure," Computers in Industry, 2019, Vol. 108, pp.121-131.

[29] S. Shafiee, K. Kristjansdottir, L. Hvam and C. Forza, How to scope configuration projects and manage the knowledge they require, Journal of Knowledge Management, vol. 22, no. 5, pp. 982 $1014,2018$.

[30] A. H. Van de Ven, Nothing is quite so practical as a good theory, Academy of Management Review, vol. 14 , no. 4, pp. 486-489, 1989.

[31] D. M. McCutcheon and J. R. Meredith, Conducting case study research in operations management, Journal of Operations Management, vol. 11, no. 3, pp. 239-256, 1993.

[32] C. Karlosson, Research methods for operations management. Routledge Taylor \& Francis Group, London, 2016.

[33] S. Ben Mahmoud-Jouini, C. Midler, V. Cruz, and N. Gaudron, How Physical Artefacts Contribute to Design Processes?, Academy of Management Proceedings, 2014, vol. 2014, no. 1, p. 14113. 